\title{
On Lester Embree, Aron Gurwitsch, AND SOME OTHER THINGS FROM THE PAST
}

\section{Sobre Lester Embree, ARON GuRWitsch \\ Y ALGUNAS OTRAS COSAS DEL PASADO}

\begin{abstract}
Alexandre Métraux
Archives Henri Poincaré, Université de Lorraine (campus Nancy) ametraux@posteo.ch
\end{abstract}

When I receives his first letter some time in 1970, I had no idea who had sent it. A Lester Embree had signed his name at the end of the typed message, by which I was most kindly invited to contribute to the Festschrift for Aron Gurwitsch. This Lester Embree, it turned out, was putting the Festschrift together. I gladly accepted, since I thus could honor Gurwitsch who would celebrate his seventieth birthday on January 17, 1971.

Lester Embree took care, with thoughtful consideration, of the text I had submitted. Since it was yet unpublished, it was offered as a private birthday present (bound together with other such gifts) to Gurwitsch. Rather than sending written thanks for the contribution to Europe, Gurwitsch suggested that we meet at Zurich in June of that year. So we did. He then thanked me for the contribution. We quickly got engaged in a daylong conversation, during which I learned that Lester Embree was one of his doctoral students. And in the summer of the same year, the selfsame doctoral student sent another letter. He informed me that he had stumbled upon an unpublished monograph, authored in German, in the cabinet of Gurwitsch's study in Manhattan. 
The intellectual (as one could have said in former times) commerce, as well as the yearlong epistolary and face-to-face interactions, with Lester Embree turned out to be from the outset something like a strange triangular relationship. He and I would either by necessity or by chance focus on Gurwitsch. The latter's life history, his work, the legal and editorial matters relating to his published and unpublished texts kept us busy (if I may say so here) until some weeks before Lester's passing away. He became my English speaking "supervising editor" for pieces of prose on any topic concerning Gurwitsch, and I would help him whenever he would face some linguistic riddle found in documents written in French or German by Gurwitsch or by some other person.

This strangely constellated dual relationship (Gurwitsch stubbornly remaining present at the background, and symbolically requiring our attention) had several consequences. Lester and I did not communicate with one another on a regular basis. It happened from time to time that we kept silent (in any sense of the word-no letters, no phone calls, no emails) for months. And then, when needed, we moved with urgent haste into sending digital mails in rows.

One day, when studying Gurwitsch's Parisian lectures on phenomenology and other topics he had addressed while being exiled in France, I got stuck in riddles I couldn't overcome without the help of historical documents. No problem, Lester signaled, no problem at all! Some weeks later, the postman delivered three parcels containing several hundred pages of photocopied material, in French, bearing dates, titles, section numbers, etc., I could not have wished for something better (or something else).

On the other hand, I guess that the fixed star called Gurwitsch to be seen at the horizon of our friendship did in a way preserve alive the contact Lester and I had on an irregular basis. Our scholarly interests diverged increasingly the longer we knew each other. He and I were initially, and in equal ways (I surmise), interested in Gurwitsch's theory of science. Or, to be a little bit more precise: this theory of science was a common ground on which to build arguments, to imagine (or materially to find) some little flaws in the phenomenological approach, or to develop some critique of some non-phenomenological approach. Thus, our stance was, to make it short, that of Gurwitschian epistemology. But on the longer run, I got more and more attracted by other theories and/or histories of science, as long as they could help grasping research practices either in the natural sciences or in the (to use an old-fashioned expression) moral sciences. Lester Embree, in 
contradistinction, remained close to the phenomenological approach. I do not know whether my issues with all sorts of approaches in the history and theory of the sciences disappointed him. However, I know that, whatever degree of disappointment may have been reached (if there had been disappointment to begin with), our dealings with one another as well as with the work(s) of Gurwitsch did not suffer too much-otherwise, we couldn't have moved along as smoothly as we did.

The last project that kept us occupied was the edition of Gurwitsch's Collected Works. Very unexciting things had to be done; we shared fits of anger at the publishing company's way of dealing with a project whose scope had nothing in common with articles submitted for peer-reviewed journals of microbiology, geology or oncology; in addition, we exchanged lots of emails on many points such as determining whether we would include some of Gurwitsch's non-English texts, or whether it would be wise to not include an early, short and not utterly substantial review of a monograph that had lost social visibility since the early 1930s.

One of the liveliest memories I keep of Lester refers to a late evening of some late December day in the 1980s (since several diaries of that epoch have disappeared-or cannot be found again-, I'm unable to determine which year of the 1980 s it was). Lester had driven to New York City. Fred Kersten, one of the then still living four future editors of the Collected Works, had flown in from Wisconsin and had also joined Alice Gurwitsch and me on 820 West End Avenue in Manhattan. The four of us had had an excellent dinner. After that, we were soberly discussing issues of copyright that had caused a slight controvery with some third party. Alice Gurwitsch suddenly got upset. By way of explaining to her that there was no reason to be upset, that we would fix the problem the next day, that there was some misunderstanding remaining unsolved from earlier days, and that this misunderstanding could be easily handled, we tried to calm and comfort her. We did not succeed. After some time, Lester urged us to stop arguing and suggested that we take a drive to Brooklyn. It was past midnight, Lester drove us in his car, he stopped at a nice spot in Brooklyn Heights: it rained, the air was saturated with winter moisture, and in front of us, there was the splendid skyline of Manhattan, timidly and dimly illuminating the silence that had befallen our tiredness. 